\title{
Serum and cerebrospinal fluid C-reactive protein levels as predictors of vasospasm in aneurysmal subarachnoid hemorrhage
}

\author{
Clinical article
}

\author{
Kostas N. Fountas, M.D., Ph.D., ${ }^{1}$ Anastasia Tasiou, M.D., ${ }^{1}$ Eftychia Z. Kapsalaki, M.D., ${ }^{2}$ \\ Konstantinos N. Paterakis, M.D., Ph.D., ${ }^{1}$ Arthur A. Grigorian, M.D., Ph.D., ${ }^{3}$ \\ Gregory P. Lee, Ph.D., ${ }^{4}$ And Joe Sam Robinson Jr., M.D. ${ }^{3}$ \\ Departments of ${ }^{1}$ Neurosurgery and ${ }^{2}$ Diagnostic Radiology, University Hospital of Larisa, School of Medicine, \\ University of Thessaly, Larisa, Greece; ${ }^{3}$ Department of Neurosurgery, Medical Center of Central Georgia, \\ School of Medicine, Mercer University, Macon; and ${ }^{4}$ Department of Neurology, Medical College of Georgia, \\ Augusta, Georgia
}

\begin{abstract}
Object. Cerebral vasospasm is a common and potentially devastating complication of aneurysmal subarachnoid hemorrhage (aSAH). Inflammatory processes seem to play a major role in the pathogenesis of vasospasm. The Creactive protein (CRP) constitutes a highly sensitive inflammatory marker. The association of elevated systemic CRP and coronary vasospasm has been well established. Additionally, elevation of the serum CRP levels has been demonstrated in patients with aSAH. The purpose of the current study was to evaluate the possible relationship between elevated CRP levels in the serum and CSF and the development of vasospasm in patients with aSAH.

Methods. A total of 41 adult patients in whom aSAH was diagnosed were included in the study. Their demographics, the admitting Glasgow Coma Scale (GCS) score, Hunt and Hess grade, Fisher grade, CT scans, digital subtraction angiography studies, and daily neurological examinations were recorded. Serial serum and CSF CRP measurements were obtained on Days $0,1,2,3,5,7$, and 9. All patients underwent either surgical or endovascular treatment within 48 hours of their admission. The outcome was evaluated using the Glasgow Outcome Scale and the modified Rankin Scale.

Results. The CRP levels in serum and CSF peaked on the 3rd postadmission day, and the CRP levels in CSF were always higher than the serum levels. Patients with lower admission GCS scores and higher Hunt and Hess and Fisher grades had statistically significantly higher levels of CRP in serum and CSF. Patients with angiographic vasospasm had higher CRP measurements in serum and CSF, in a statistically significant fashion ( $p<0.0001)$. Additionally, patients with higher CRP levels in serum and CSF had less favorable outcome in this cohort.

Conclusions. Patients with aSAH who had high Hunt and Hess and Fisher grades and low GCS scores showed elevated CRP levels in their CSF and serum. Furthermore, patients developing angiographically proven vasospasm demonstrated significantly elevated CRP levels in serum and CSF, and increased CRP measurements were strongly associated with poor clinical outcome in this cohort. (DOI: 10.3171/2009.2.FOCUS08311)
\end{abstract}

\section{KeY Words • aneurysm • C-reactive protein • digital subtraction angiography • inflammation • subarachnoid hemorrhage • vasospasm}

A NEURYSMAL subarachnoid hemorrhage constitutes a devastating and complicated clinical entity. Despite the recent advances in its early detection, diagnosis, and its proper treatment, the overall outcome

\footnotetext{
Abbreviations used in this paper: aSAH $=$ aneurysmal subarachnoid hemorrhage; $\mathrm{CRP}=\mathrm{C}$-reactive protein; $\mathrm{DIND}=$ delayed ischemic neurological deficit; DS = digital subtraction; GCS = Glasgow Coma Scale; GOS = Glasgow Outcome Scale; IL = interleukin; $\mathrm{mRS}=$ modified Rankin Scale .
}

of patients with aSAH remains poor. ${ }^{11,58}$ Approximately $50 \%$ of patients suffering aSAH will die, $15 \%$ of them will become severely disabled, and only 20-35\% will return to normal life and activities. . $^{1,15,43,58}$

Cerebral vasospasm remains the most troublesome complication of aSAH. It is associated with high morbidity and mortality rates, even after successfully treating the ruptured aneurysm. The occurrence of cerebral vasospasm varies significantly. It has been demonstrated to be as high as $70 \%$ based on angiographic findings, and 
TABLE 1: Anatomical location of 46 treated aneurysms in 41 patients with aSAH

\begin{tabular}{lc}
\hline \multicolumn{1}{c}{ Location of Lesion } & No. of Aneurysms \\
\hline posterior communicating artery & 14 \\
anterior communicating artery & 11 \\
middle cerebral artery & 7 \\
internal carotid artery & 5 \\
basilar artery & 5 \\
anterior choroidal artery & 2 \\
posterior inferior cerebellar artery & 2 \\
\hline
\end{tabular}

in $20-30 \%$ of patients, vasospasm is responsible for the development of a DIND. ${ }^{15,23,29}$

Several theories have been proposed in an attempt to explain the underlying pathophysiological mechanisms of cerebral vasospasm.7,17,18,37,53,65 However, none of the proposed theories has been experimentally proven, and the underlying mechanism causing this complex problem remains unknown. Among these theories, a relatively recent one postulates that an inflammation-based pathogenetic mechanism is implicated in the development of coronary vasospasm. ${ }^{11,55}$ Previous experimental and clinical studies have demonstrated that inflammatory changes occur in spastic coronary arteries..$^{4,19,25,26,61,65}$ It has been demonstrated that eosinophilic cell counts and plasma fibrinogen levels could predict the severity of vasospastic angina pectoris. ${ }^{65}$ Additionally, previous clinical studies have shown that elevated levels of high-sensitivity CRP could predict the development of coronary vasospasm. ${ }^{26}$ The measurement of sensitive inflammatory markers such as CRP significantly increases our ability to predict with accuracy and possibly to prevent or appropriately treat coronary thrombotic events. ${ }^{4,19,25,26,61,65}$ Furthermore, elevated CRP is associated with increased risk of a subsequent myocardial infarction.

A similar inflammatory response affecting the cerebral vasculature is elicited in cases of aSAH via the release of various cytokines such as IL-6, IL-1, and tumor necrosis factor; increased leukocyte trafficking; and macrophage and complement cascade activation..$^{11,55}$ Additionally, it has been demonstrated that CRP, an acute-phase protein, which is a highly sensitive indicator of inflammatory response, is produced by hepatocytes in response to increased production of IL-6. ${ }^{6,44,63}$ Because IL-6 has been associated with the development of cerebral vasospasm, increased levels of CRP at the time of the patients' admissions and early in their postictal courses might have some predictive value in the early detection and proper management of vasospasm.

In our current study, we present our results from measuring the CRP levels in the serum and CSF of patients suffering aSAH, and we explore the relationship of systemic and CSF CRP levels and the development of cerebral vasospasm.

\section{Methods}

Our prospective clinical study was approved by the institutional review boards of the participating institutions,
TABLE 2: Number of aneurysms with small, large, or giant domes in 41 patients with aSAH

\begin{tabular}{lc}
\hline Max Diameter of Aneurysmal Dome* & No. of Aneurysms \\
\hline$<10 \mathrm{~mm}$ & 9 \\
$10-25 \mathrm{~mm}$ & 31 \\
$>25 \mathrm{~mm}$ & 6 \\
\hline * The dome's largest diameter was measured on the preoperative DS \\
angiography study.
\end{tabular}

and the collection and analysis of all data were performed according to the current Health Insurance Portability and Accountability Act regulations. A detailed written consent form was obtained from all participants or from their legal representatives or next of kin in those cases in which the patient was unable to consent. The inclusion criteria of our study were as follows: 1) diagnosis of aSAH established by a CT scan and a subsequent 4-vessel DS angiography study; 2) patient age $>18$ years; 3 ) patient admission to our institutions within the first 24 hours postictus; 4) patient's surgical or endovascular treatment within 48 hours from admission to our hospitals; 5) pre- and posttreatment DS angiography for vasospasm documentation purposes; and 6) external ventriculostomy insertion. Patients with concomitant or recent acute myocardial infection, history of recent ( $\leq 30$ days) surgery prior to the ictal event, and/or clinical or laboratory evidence of chronic systemic infection were excluded from our study. In addition, patients who received no external ventriculostomy or who died before completing 10 days of treatment were excluded from our current study.

The study covered a 4-year period (2004-2007). A total of 286 patients was admitted during this period with an established diagnosis of aSAH. However, only $41 \mathrm{pa}-$ tients met our inclusion criteria and participated in our study. There were 25 men and 16 women, with a mean age of 51.8 years and ages ranging between 34 and 72 years. A total of 46 aneurysms were identified in our cohort.

The participants' demographic data, their admission GCS scores, Hunt and Hess grades, and Fisher grades, their detailed daily neurological examinations, and their head CT scans were recorded. A standard 4-vessel DS angiography study was obtained on admission in all patients, and another DS angiography was obtained between the 7th and 10th posttreatment day. An intraoperative DS angiography study was performed in $28(68.3 \%)$ of our 41 patients. An external ventriculostomy was made in all participants ipsilaterally to the blood clot if there were any intraventricular clots, or in the right lateral ventricle in cases with no intraventricular hemorrhage or symmetrical intraventricular hemorrhage. The ventricular catheter was tunneled under the skin and was routinely externalized $2.5-3 \mathrm{~cm}$ away from the entry site. Surgical clipping was performed in $33(80.5 \%)$ of the 41 patients for $35(76.1 \%)$ of the 46 aneurysms, whereas endovascular treatment was used in $8(19.5 \%)$ of the 41 patients for $11(23.9 \%)$ of the 46 aneurysms. The selection of surgical versus endovascular treatment was based on criteria such as the anatomical location of the lesion, the size 


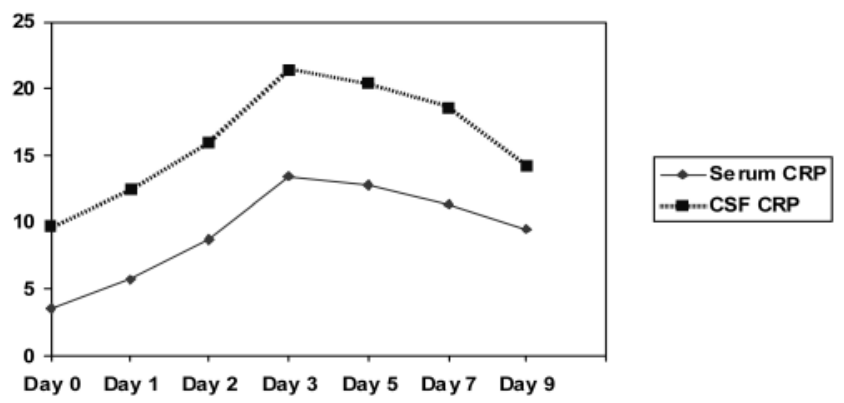

FIG. 1. Schematic representation of summated measured CRP levels in the serum and CSF of our patients.

and morphological features of the aneurysm, the presence of multiple aneurysms, the presence of mass effect caused by the aneurysm and/or an associated hematoma, the patient's neurological and general medical condition, and the patient's preference. It has to be emphasized that either surgical or endovascular treatment was performed within 48 hours of patient admission.

The CRP level in serum and CSF was measured in each patient on Days 0 (on admission to our centers), 1, $2,3,5,7$, and 9 , and the measurements obtained were recorded. Blood serum specimens were collected from an inserted venous line, whereas the CSF specimens were collected through an external ventriculostomy. The CRP levels were measured using a nephelometric methodology. All the CRP measurements were expressed as mil-

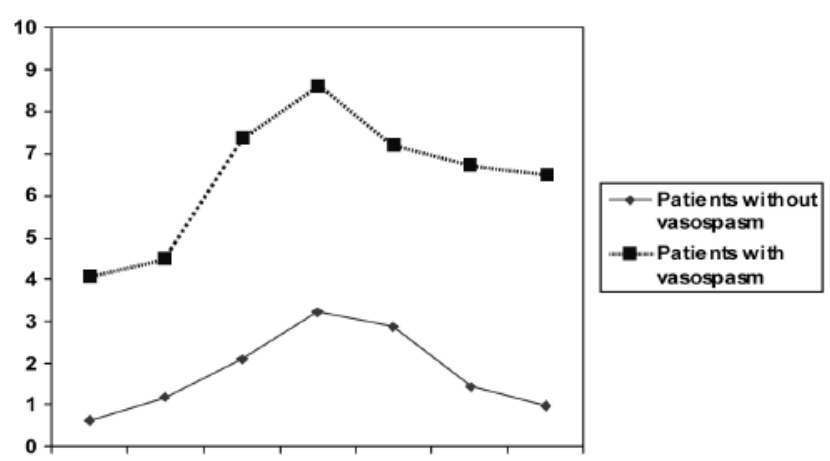

Day 0 Day 1 Day 2 Day 3 Day 5 Day 7 Day 9

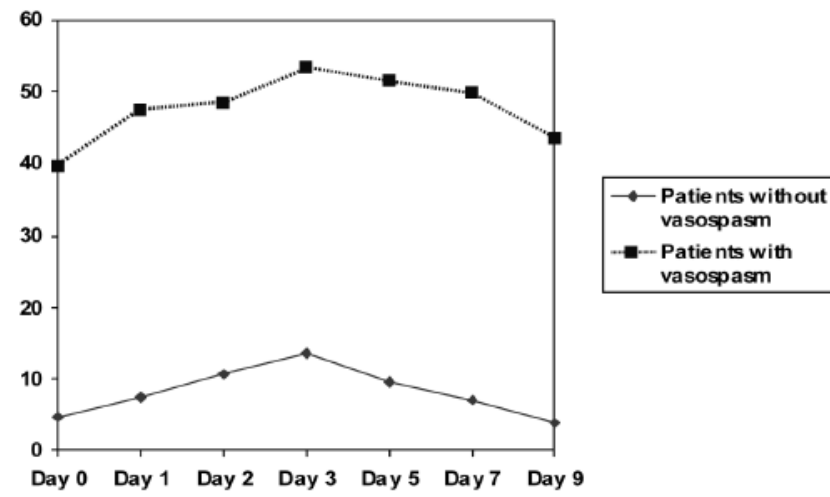

FIG. 2. Upper: Schematic representation of CRP levels in serum in patients with and without vasospasm. Lower: Schematic representation of CRP levels in CSF in patients with and without vasospasm.
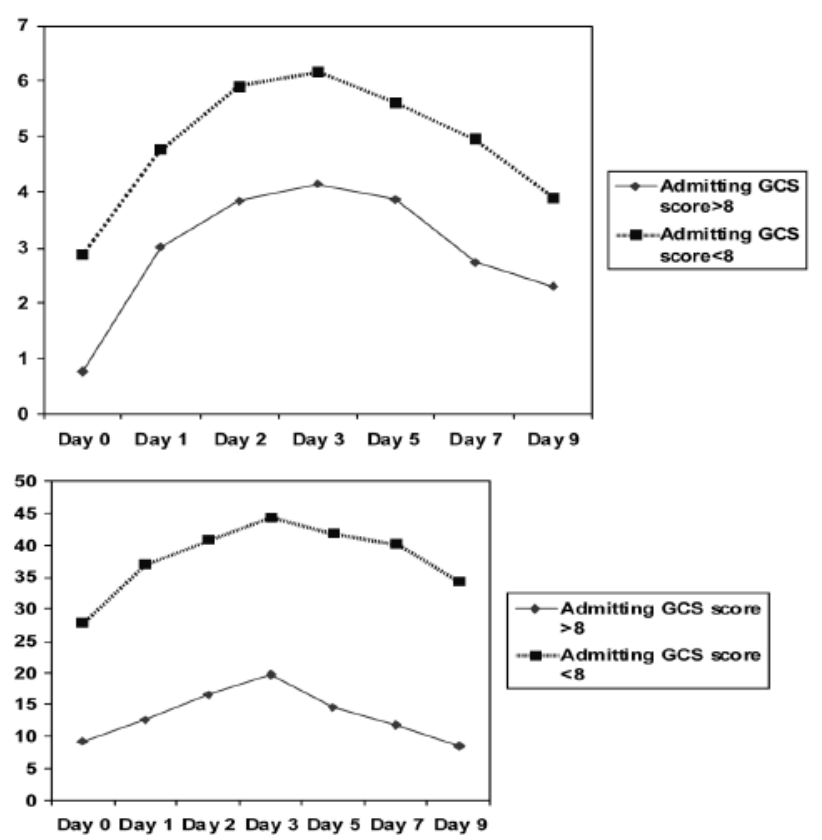

FIG. 3. Upper: Schematic representation of CRP levels in serum with regard to the admission GCS score. Lower: Schematic representation of CRP levels in CSF with regard to the admission GCS score.

ligrams/liter. The mean serum and CSF values were calculated for each participant.

The patients' clinical outcome was evaluated using the GOS and $\mathrm{mRS}$ at discharge from our institutions, and all participants' scores were recorded.

\section{Results}

The anatomical location of the lesions and the preoperatively measured maximum diameter of the aneurysmal dome in our cohort are summarized in Tables 1 and 2, respectively. The admission GCS scores ranged between 4 and 15 (mean 11.7). The Hunt and Hess scores on admission ranged between I and V (mean 2.5), and the Fisher grades in our patients ranged between 1 and 4 (mean 1.9). The GOS scores on discharge ranged between 2 and 5 (mean 4.3), and the range of mRS scores was 0-5 (mean 1.1). Analytical data obtained in our patients are summarized in Table 3.

In regard to the measured CRP levels, there was a progressive increase in the CRP levels from the admission to the 3rd postadmission day (3rd or 4th postictal day), which was followed by a slow decrease toward the 9th postadmission day (Fig. 1). There was a parallel course of increase in the CRP levels in CSF and serum. The observed CRP levels in the CSF were significantly higher than the levels of CRP in the serum throughout the entire postictal period (paired t-test methodology; $\mathrm{t}=$ 6.547, $\mathrm{p}<0.0001$ ) (Fig. 1).

Angiographic vasospasm was detected in 15 (36.6\%) of our 41 patients in the DS angiography studies obtained posttreatment. Analysis of our angiographic data demonstrated that there was a regional pattern of vasospasm, affecting mainly the parent and adjacent vessels in $9(21.9 \%)$ 


\section{K. N. Fountas et al.}

TABLE 3: Demographic data, neurological grades on admission, postoperative findings, and scores at discharge in 41 patients with aSAH*

\begin{tabular}{|c|c|c|c|c|c|c|c|}
\hline Case No. & Age (yrs), Sex & GCS Score & H \& H Grade & $\begin{array}{l}\text { Fisher } \\
\text { Grade }\end{array}$ & $\begin{array}{l}\text { Vasospasm on } \\
\text { Postop DSA }\end{array}$ & GOS Score & mRS Score \\
\hline 1 & $54, \mathrm{M}$ & 15 & $\|$ & 1 & + & 5 & 0 \\
\hline 2 & $46, \mathrm{M}$ & 15 & I & 1 & - & 5 & 0 \\
\hline 3 & $69, \mathrm{~F}$ & 9 & III & 3 & + & 4 & 2 \\
\hline 4 & $72, \mathrm{M}$ & 12 & $\|$ & 2 & + & 5 & 0 \\
\hline 5 & $39, F$ & 14 & I & 1 & + & 5 & 0 \\
\hline 6 & $45, \mathrm{M}$ & 15 & I & 1 & - & 5 & 0 \\
\hline 7 & $51, \mathrm{~F}$ & 6 & IV & 4 & + & 3 & 4 \\
\hline 8 & $62, \mathrm{M}$ & 13 & $\|$ & 3 & - & 5 & 0 \\
\hline 9 & $44, M$ & 5 & I & 1 & - & 5 & 0 \\
\hline 10 & $59, \mathrm{~F}$ & 12 & III & 3 & + & 4 & 2 \\
\hline 11 & $62, \mathrm{M}$ & 15 & $\|$ & 1 & - & 5 & 0 \\
\hline 12 & $40, M$ & 8 & IV & 3 & + & 4 & 2 \\
\hline 13 & $58, F$ & 14 & $\|$ & 1 & - & 5 & 0 \\
\hline 14 & $35, F$ & 15 & I & 1 & - & 5 & 0 \\
\hline 15 & $68, M$ & 9 & III & 2 & + & 4 & 2 \\
\hline 16 & $55, \mathrm{M}$ & 14 & $\|$ & 1 & - & 4 & 2 \\
\hline 17 & $46, \mathrm{M}$ & 12 & III & 2 & + & 5 & 1 \\
\hline 18 & $65, \mathrm{~F}$ & 15 & 1 & 1 & - & 5 & 0 \\
\hline 19 & $40, \mathrm{~F}$ & 15 & I & 1 & - & 5 & 0 \\
\hline 20 & $57, \mathrm{M}$ & 13 & $\|$ & 1 & - & 5 & 1 \\
\hline 21 & $61, \mathrm{M}$ & 8 & IV & 2 & - & 4 & 2 \\
\hline 22 & $65, M$ & 15 & I & 1 & - & 5 & 0 \\
\hline 23 & $59, \mathrm{M}$ & 7 & IV & 3 & - & 3 & 4 \\
\hline 24 & $60, F$ & 14 & $\|$ & 1 & - & 5 & 0 \\
\hline 25 & $45, M$ & 13 & $\|$ & 1 & - & 5 & 0 \\
\hline 26 & $39, \mathrm{~F}$ & 12 & III & 2 & + & 4 & 2 \\
\hline 27 & 42, M & 6 & V & 4 & - & 3 & 4 \\
\hline 28 & $34, \mathrm{M}$ & 8 & IV & 3 & + & 3 & 4 \\
\hline 29 & $61, \mathrm{~F}$ & 15 & I & 1 & - & 5 & 0 \\
\hline 30 & $54, \mathrm{M}$ & 7 & III & 3 & + & 4 & 2 \\
\hline 31 & $47, \mathrm{M}$ & 4 & V & 4 & + & 2 & 5 \\
\hline 32 & $58, M$ & 15 & I & 1 & - & 5 & 0 \\
\hline 33 & $47, \mathrm{~F}$ & 12 & $\|$ & 2 & + & 5 & 0 \\
\hline 34 & $38, F$ & 13 & III & 2 & + & 5 & 0 \\
\hline 35 & $41, \mathrm{~F}$ & 5 & V & 4 & - & 2 & 5 \\
\hline 36 & $66, M$ & 15 & 1 & 1 & - & 5 & 0 \\
\hline 37 & $45, \mathrm{~F}$ & 11 & III & 3 & - & 4 & 2 \\
\hline 38 & $54, \mathrm{M}$ & 13 & $\|$ & 2 & - & 5 & 0 \\
\hline 39 & $38, M$ & 9 & IV & 3 & - & 5 & 0 \\
\hline 40 & $44, \mathrm{~F}$ & 10 & $\|$ & 3 & - & 5 & 0 \\
\hline 41 & $60, M$ & 14 & $\|$ & 1 & - & 5 & 0 \\
\hline
\end{tabular}

* DSA = digital subtraction angiography; $\mathrm{H} \& \mathrm{H}=$ Hunt \& Hess; + = present; - = absent.

of our 41 patients, whereas in $6(14.6 \%)$ of 41 , global vasospasm was evident. Interestingly, clinical symptoms caused by the observed cerebral vasospasm developed in $8(19.5 \%)$ of 41 patients in our cohort. These symptoms were managed solely medically in 6 cases, whereas in the remaining 2 cases intravascular balloon angioplasty was necessary.

Statistical analysis of our data showed that patients developing angiographic vasospasm in our cohort had higher CRP levels in serum (Fig. 2 upper). This differ- 


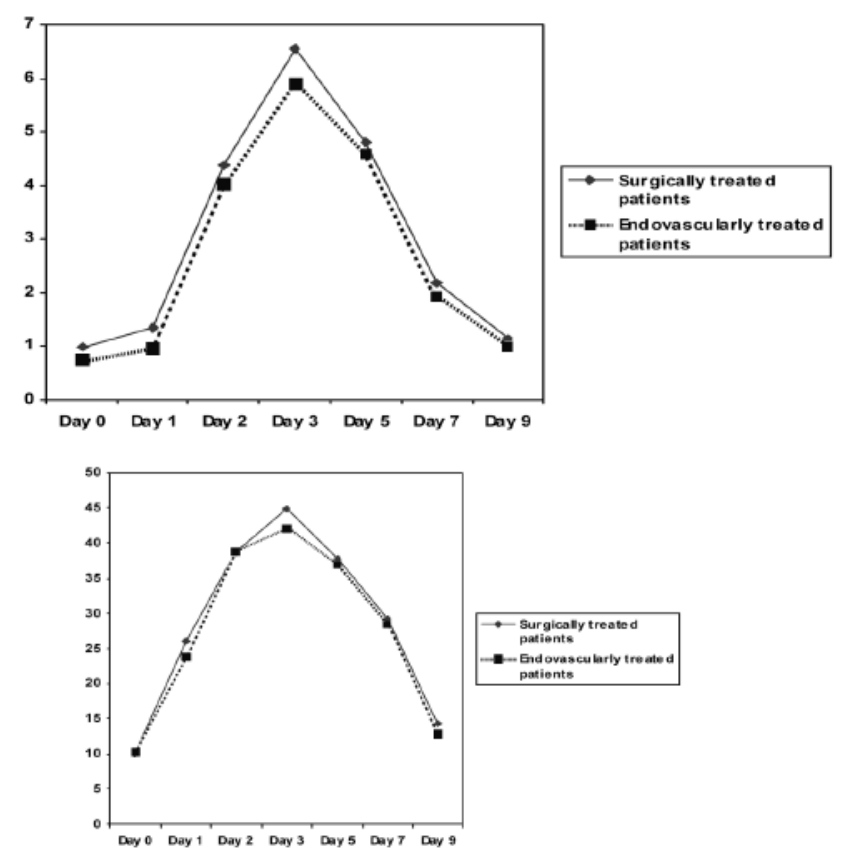

FIG. 4. Upper: Graph showing CRP measurements in serum in surgically versus endovascularly treated patients in our cohort. Lower: Graph showing CRP measurements in CSF in surgically versus endovascularly treated patients in our study.

ence reached the level of statistical significance (unpaired $\mathrm{t}$-test methodology; $\mathrm{df}=39, \mathrm{t}=-4.678, \mathrm{p}<0.0001)$. Similarly, patients with angiographically proven vasospasm demonstrated higher CRP levels in CSF, in a statistically significant fashion (unpaired t-test methodology; df $=39$, $\mathrm{t}=-4.201, \mathrm{p}<0.0001$ ) (Fig. 2 lower). On the contrary, the difference in occurrence of angiographic vasospasm between patients undergoing surgical clipping and those undergoing endovascular coil insertion was not statistically significant (chi-square statistical methodology; $\chi^{2}=$ $0.004, \mathrm{df}=1, \mathrm{p}=0.95$ ). The strength of our last statistical analysis is very limited, however, due to the small number of participants in the endovascular group.

In regard to the admission GCS score and the serum CRP levels, we found that patients with lower GCS scores had increased CRP measurements in serum (correlation coefficient methodology; $\mathrm{z}=-8.139, \mathrm{p}<0.0001, \mathrm{r}=$ -0.87) (Fig. 3 upper) and CSF ( $\mathrm{z}=-6.443, \mathrm{p}<0.0001, \mathrm{r}$ $=-0.78$ ) (Fig. 3 lower). Low admission GCS scores were significantly inversely correlated with high CRP values in serum and CSF. Likewise, patients with higher Hunt and Hess grades on admission developed significantly higher CRP levels in serum (correlation coefficient methodology; $\mathrm{z}=6.244, \mathrm{p}<0.0001, \mathrm{r}=0.77)$ and $\mathrm{CSF}(\mathrm{z}=5.850$, $\mathrm{p}<0.0001, \mathrm{r}=0.74)$. Similarly, patients with higher admission Fisher grades showed increased levels of CRP in serum (correlation coefficient methodology; $\mathrm{z}=7.132$, $\mathrm{p}$ $<0.0001, \mathrm{r}=0.82)$ and $\mathrm{CSF}(\mathrm{z}=6.700, \mathrm{p}<0.0001, \mathrm{r}=$ $0.80)$.

There was no statistically significant difference in the serum CRP levels between the group of patients undergoing surgical clipping and those undergoing endovascular
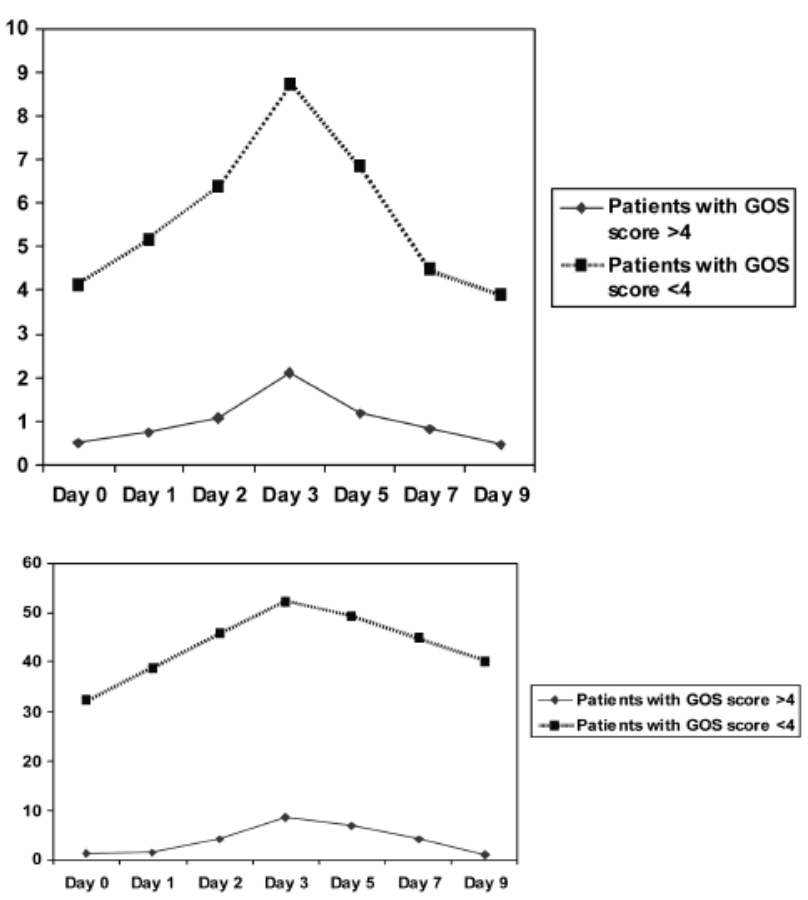

FIG. 5. Upper: Schematic representation of CRP measurements in serum in patients with GOS score $\geq 4$ versus patients with GOS score $<4$ at discharge. Lower: Schematic representation of CRP levels in CSF in patients with GOS score $\geq 4$ versus patients with GOS score < 4 at discharge.

coil occlusion, although the surgical group had higher serum CRP levels (unpaired t-test methodology; $\mathrm{t}=1.151, \mathrm{p}$ $=0.2569$ ) (Fig. 4 upper). Likewise, the CRP differences in CSF between these 2 groups did not reach levels of statistical significance $(t=0.650, p=0.5193)$ (Fig. 4 lower). It has to be emphasized, however, that the strength of this comparison is very limited due to the small number of patients in the endovascularly treated group. In regard to their GOS scores, patients with higher CRP levels in serum (correlation coefficient methodology; $\mathrm{z}=-5.861$, $\mathrm{p}<$ 0.0001, $\mathrm{r}=-0.74$ ) (Fig. 5 upper) and CSF ( $\mathrm{z}=-5.091, \mathrm{p}$ $<0.0001, \mathrm{r}=-0.68$ ) (Fig. 5 lower) had less favorable outcomes. A statistically significant inverse correlation was established in our series between CRP levels (in serum and CSF) and GOS scores. A similar statistically strong relationship was found between $\mathrm{mRS}$ scores on discharge and CRP measurements in serum (correlation coefficient methodology; $\mathrm{z}=6.062, \mathrm{p}<0.0001, \mathrm{r}=0.76)$ and $\mathrm{CSF}(\mathrm{z}$ $=5.304, \mathrm{p}<0.0001, \mathrm{r}=0.70)$.

\section{Discussion}

The role of inflammation in the development and maintenance of cerebral vasospasm has been previously demonstrated. ${ }^{11,55}$ Several animal studies and clinical series have shown that inflammatory processes contribute to the pathogenesis of cerebral vasospasm. ${ }^{33,54,57}$ It is well known that leukocyte trafficking increases in SAH due to a breakdown of the blood-brain barrier. ${ }^{5,8-11,14,23,52,66}$ Increased levels of various soluble adhesion molecules 
(such as E-selectin, intercellular adhesion molecule-1, and vascular adhesion molecule-1) and cytokines (such as IL-6 and IL-1) have been noted in the plasma and CSF of patients with SAH..$^{11,12,16,22,30,54,57,60}$ Kubo et al. ${ }^{34}$ demonstrated that serum concentrations of intercellular adhesion molecule-1 and vascular adhesion molecule-1 were significantly higher among patients suffering aSAH, and that their increased serum levels of these molecules were associated with increased incidence of DIND. An increased concentration of platelet-activating factors was found in the jugular venous blood samples of patients with $\mathrm{SAH},{ }^{22}$ and tumor necrosis factor- $\alpha$ levels increased after SAH, and this increased concentration was correlated in time and extent with increased blood flow velocities of the basal cerebral arteries as measured by transcranial Doppler ultrasonography. ${ }^{11,12}$ Furthermore, increased levels of immunoglobulins and complement factors have been found in the serum and cerebral vessel walls during vasospasm. ${ }^{11,24,30,48,50,51}$ Kubota et al., ${ }^{35}$ in an animal model of $\mathrm{SAH}$, found that activated macrophages and T-cell counts were elevated in such circumstances, with peak levels occurring 2 days after the ictal event. In addition, it has been demonstrated that endothelin-1, which is produced by activated leukocytes accompanying an inflammatory response, is involved in the development of cerebral vasospasm. ${ }^{11}$ Furthermore, recent series of animal models of SAH have shown changes in the gene expression of inflammation-related products. ${ }^{1,11,16,21,31,32,36,38-42,45-47,49,59,62,67}$ Cyclooxygenase (also called COX-2), which is known to be an important component in many inflammatory responses, is upregulated after induced SAH in canine and rabbit basilar arteries. ${ }^{49,64}$ Macdonald and Weir, ${ }^{38}$ in their SAH primate model studies, have demonstrated the upregulation of certain inflammation-related genes.

It is apparent that multiple inflammatory mechanisms are directly involved in the pathogenesis of cerebral vasospasm. It is also well established that CRP is a sensitive inflammatory marker. Interleukin- 6 constitutes a strong stimulus for CRP synthesis by hepatocytes. ${ }^{44,63}$ Additionally, IL-1, which has been implicated in the pathogenesis of cerebral vasospasm, also represents a strong stimulus for CRP synthesis. ${ }^{63}$ Therefore, elevated concentrations of CRP may well be associated with an increased possibility of developing cerebral vasospasm and subsequently a DIND. ${ }^{34}$

Our results showed that elevated CRP levels in serum and CSF were associated with increased incidence of angiographic vasospasm, based on the DS angiography findings in our cohort. Additionally, there was a strong inverse correlation between admitting GCS scores and CRP levels in serum and CSF $(r=-0.87$ and $r=-0.78$, respectively). The admission Hunt and Hess and Fisher grades were also correlated in a statistically significant fashion with the CRP measurements in serum and CSF in our cohort. Furthermore, the elevated CSF and serum CRP levels that we observed were associated with worse clinical outcome, as expressed in GOS and mRS scores in our cohort. It is noteworthy that the CRP levels were always higher in CSF than in serum in all patients throughout the entire postictal period. This may be explained by the fact that the underlying aSAH caused a disruption of the blood-brain barrier, which allowed massive intrathecal CRP transportation as an immediate systemic inflammatory response to the presence of blood and blood clots in the subarachnoid space. We found no statistically significant difference in the occurrence of angiographic vasospasm between patients undergoing surgical treatment and those undergoing endovascular coil occlusion. Interestingly, the surgically treated group demonstrated higher levels of CRP in serum and CSF compared with those who were endovascularly treated; however, this difference did not reach levels of statistical significance. It has to be emphasized that the extraction of any powerful conclusions from these last comparisons is impossible due to the very limited number of endovascularly treated patients in our study.

Our current findings are in agreement with the observations of other clinical investigators. ${ }^{2,28,34,56,63}$ Bengzon et al. examined the serum CRP levels of patients undergoing standard neurosurgical procedures in a prospective clinical study. They found that all their patients demonstrated elevated CRP levels postoperatively, and the magnitude of the CRP elevation was associated with the extent of the surgical trauma. They reported, however, that patients with aSAH showed the highest serum CRP increases, and they postulated that the SAH and not the surgical trauma itself had most likely contributed to the significant serum CRP elevation. In a previous retrospective clinical study, by analyzing the patients' admission Hunt and Hess grades, Rothoerl et al. ${ }^{56}$ found that serum CRP levels could provide independent information regarding the severity of brain injury resulting from the initial SAH. They concluded that the higher the serum CRP level, the poorer the clinical outcome was. Furthermore, the time pattern of serum CRP increase in their cohort was similar to the one observed in our current series. They noted a peak serum CRP concentration on the 3rd and 4th postictal days and gradual, slow decrease of the measurements obtained after the 5th postictal day, a pattern identical to the one observed in our series. Likewise, Takizawa et al., ${ }^{63}$ in their study examining CSF samples of patients suffering SAH by using enzyme-linked immunosorbent assays and Western blot analysis, found that CRP levels in CSF were significantly increased, and the CRP in CSF peaked between the 2nd and 3rd postictal days. On the contrary, Berger et al. ${ }^{3}$ reported that serum CRP reached a peak on the 2 nd postictal day in their series. Kacira et al. ${ }^{28}$ reported increased high-sensitivity CRP levels in serum and CSF in patients with aSAH compared with healthy controls. Interestingly, they found that elevated serum and CSF high-sensitivity CRP was correlated to increased measurements of caspase-3 and neuron-specific enolase, which are markers of apoptosis and neuronal tissue damage, respectively. In a previous study, Fountas et al. ${ }^{13}$ found that patients with aSAH who had low $(<8)$ GCS scores and high (> III) Hunt and Hess grades had significantly higher serum CRP levels, and that an increased serum CRP level was positively correlated with poor clinical outcome. Their findings are in agreement with the data in our current study.

Unfortunately, the clinical significance of elevated 
serum CRP measurements in patients sustaining aSAH is confounded by the fact that most of these patients may have other concomitant systemic infections or pathological conditions that could potentially result in increased CRP serum concentrations. Additionally, the surgical manipulation in these patients (arterial catheterization, surgical clipping, endovascular coil occlusion, ventriculostomy insertion) could influence the systemic CRP levels. However, our strict inclusion criteria minimized the influence of other confounding factors such as systemic infection or other concomitant heart conditions. Moreover, obtaining CRP measurements in CSF could further minimize the effect of other confounding factors in our current study.

It has to be emphasized however, that our study carries significant limitations. First, the size of our clinical series was limited, and therefore the statistical strength of our conclusions was also limited. Second, it is well known that clinical outcome in patients with aSAH is multifactorial. The association between CRP levels systemically and in CSF with the clinical outcome may well be influenced by other parameters in a complex and frequently unpredictable way. In addition, CRP represents a sensitive but nonspecific inflammatory marker. Although we attempted to minimize the presence of other systemic or confounding factors in our study by applying strict inclusion criteria, there were certain issues that could not be addressed. The insidious onset of a CNS and/or systemic infection may contribute to serum CRP elevation and significantly confound the CRP predictive value for early vasospasm detection. Furthermore, any neurosurgical intervention per se may well increase the serum CRP levels, ${ }^{2}$ although there are no data as far as we know regarding the CRP response in CSF to standard neurosurgical procedures. It has been reported, however, that CRP levels in CSF are elevated in patients with severe head trauma, ${ }^{20,27}$ a finding that may further support our current results that the postictal elevated CRP levels in CSF are mainly caused by the aSAH insult to the brain parenchyma. A large-scale, multiinstitutional, prospective clinical study is necessary to validate our results and to determine the role of CRP in serum and/or CSF in the identification of patients at high risk for developing cerebral vasospasm.

\section{Conclusions}

Our prospective clinical study showed that patients with aSAH who were admitted with low GCS scores and high Hunt and Hess and Fisher grades had elevated CRP levels in serum and CSF. The CRP measurements in the CSF were higher than the serum CRP values in all our patients throughout the entire postictal period. Patients developing angiographic vasospasm demonstrated increased levels of CRP in serum and CSF in our cohort. In addition, the CRP levels in serum and CSF were associated with poor clinical outcome in a statistically significant fashion in our study. Further validation of our results is necessary to define the prognostic role of CRP in identifying patients who are at high risk for developing postictal cerebral vasospasm secondary to aSAH.

\section{Disclaimer}

The authors report no conflict of interest concerning the materials or methods used in this study or the findings specified in this paper.

\section{References}

1. Aihara Y, Kasuya H, Onda H, Hori T, Takeda J: Quantitative analysis of gene expressions related to inflammation in canine spastic artery after subarachnoid hemorrhage. Stroke 32:212-217, 2001

2. Bengzon J, Grubb A, Bune A, Heillstrom K, Lindstrom V, Brandt L: C-reactive protein levels following standard neurosurgical procedures. Acta Neurochir (Wien) 145:667-671, 2003

3. Berger MM, Soguel L, Shenkin A, Revelly JP, Pinget C, Baines $\mathrm{M}$, et al: Influence of early antioxidant supplements on clinical evolution and organ function in critically ill cardiac surgery, major trauma, and subarachnoid hemorrhage patients. Crit Care 12:R101, 2008

4. Berk BC, Weintraub WS, Alexander RW: Elevation of Creactive protein in "active" coronary artery disease. Am J Cardiol 65:168-172, 1990

5. Bundy GM, Merchant RE: Basic research applied to neurosurgery: lymphocyte trafficking to the central nervous system. Neurosurg Q 6:51-68, 1996

6. Carr WP: The role of the laboratory in rheumatology. Acutephase proteins. Clin Rheum Dis 9:227-239, 1983

7. Dietrich HH, Dacey RG Jr: Molecular keys to the problems of cerebral vasospasm. Neurosurgery 46:517-530, 2000

8. Doczi T: The pathogenetic and prognostic significance of blood-brain barrier damage at the acute stage of aneurysmal subarachnoid hemorrhage. Clinical and experimental studies. Acta Neurochir (Wien) 77:110-132, 1985

9. Doczi T, Ambrose J, O'Laoire S: Significance of contrast enhancement after subarachnoid hemorrhage. J Neurosurg 60:335-342, 1984

10. Doczi T, Joo F, Sonkodi S, Adam G: Blood-brain barrier damage during the acute stage of subarachnoid hemorrhage, as exemplified by a new animal model. Neurosurgery 18:733-739, 1986

11. Dumont AS, Dumont RJ, Chow MM, Lin C, Calisaneller T, Ley KF, et al: Cerebral vasospasm after subarachnoid hemorrhage: putative role of inflammation. Neurosurgery 53:123135,2003

12. Fassbender K, Hodapp B, Rossol S, Bertsch T, Schmeck $\mathrm{J}$, Schutt S, et al: Inflammatory cytokines in subarachnoid hemorrhage: association with abnormal blood flow velocities in basal cerebral arteries. J Neurol Neurosurg Psychiatry 70:534-537, 2001

13. Fountas KN, Kassam M, Machinis TG, Dimopoulos VG, Robinson JS III, Ajjan M, et al: C-reactive protein might predict outcome in aneurysmal subarachnoid hemorrhage. Acta Neurochir Suppl (Wien) 104:377-381, 2008

14. Germano A, Davella D, Cicciarello R, Hayes RL, Tomasello F: Blood brain barrier permeability changes after experimental subarachnoid hemorrhage. Neurosurgery 30:882-886, 1992

15. Haley EJ, Kassell NF, Torner JC: The International Cooperative Study on the timing of aneurysm surgery: the North American experience. Stroke 23:205-214, 1992

16. Handa Y, Kubota T, Kaneko M, Tsuchida A, Kobayashi H, Kawano H, et al: Expression of intercellular adhesion molecule 1 (ICAM-1) on the cerebral artery following subarachnoid hemorrhage in rats. Acta Neurochir (Wien) 132:92-97, 1995

17. Hansen-Schwartz J: Cerebral vasospasm: a consideration of the various cellular mechanisms involved in the pathophysiology. Neurocrit Care 1:235-246 71, 2004 
18. Harrod CG, Bendok BR, Batjer HH: Prediction of cerebral vasospasm in patients presenting with aneurysmal subarachnoid hemorrhage: a review. Neurosurgery 56:633-654, 2005

19. Heilbronn LK, Clifton PM: C-reactive protein and coronary artery disease: influence of obesity, caloric restriction and weight loss. J Nutr Biochem 13:316-321, 2002

20. Hergenroeder G, Redell JB, Moore AN, Dubinsky WP, Funk RT, Crommett J, et al: Identification of serum biomarkers in brain-injured adults: potential for predicting elevated intracranial pressure. J Neurotrauma 25:79-93, 2008

21. Hino A, Tokuyama Y, Kobayashi M, Yano M, Weir B, Takeda $\mathrm{J}$, et al: Increased expression of endothelin B receptor mRNA following subarachnoid hemorrhage in monkeys. J Cereb Blood Flow Metab 16:688-697, 1996

22. Hirashima Y, Nakamura S, Endo S, Kuwayama N, Naruse Y, Takaku A: Elevation of platelet activating factor, inflammatory cytokines, and coagulation factors in the internal jugular vein of patients with subarachnoid hemorrhage. Neurochem Res 22:1249-1255, 1997

23. Ho HW, Batjer HH: Aneurysmal subarachnoid hemorrhage: pathophysiology and sequelae in: Batjer HH (ed) Cerebrovascular Disease. Lippincott-Raven Publishers, Philadelphia, 1997, pp 889-899

24. Hoshi T, Shimizu T, Kito K, Yamasaki N, Takahashi K, Takahashi M, et al: Immunological study of late cerebral vasospasm in subarachnoid hemorrhage: detection of immunoglobulins, C3, and fibrinogen in cerebral arterial walls by immunofluorescence method. Neuro Med Chir (Tokyo) 24:647-654, 1984

25. Hung MJ, Cherng WJ, Cheng CW, Yang NI: Effect of antispastic agents (calcium antagonists and/or isosorbide dinitrate) on high-sensitivity $\mathrm{C}$-reactive protein in patients with coronary vasospastic angina pectoris and no hemodynamically significant coronary artery disease. Am J Cardiol 95:84-87, 2005

26. Hung MJ, Cherng WJ, Yang NI, Cheng CW, Li LF: Relation of high-sensitivity C-reactive protein level with coronary vasospastic angina pectoris in patients without hemodynamically significant coronary artery disease. Am J Cardiol 96:14841490,2005

27. Is M, Coskun A, Sanus GZ, Tanriverdi T, Kafadar AM, Hanimoglu $\mathrm{H}$, et al: High-sensitivity C-reactive protein levels in cerebrospinal fluid and serum in severe head injury: relationship to tumor necrosis factor-alpha and interleukin-6. J Clin Neurosci 14:1163-1171, 2007

28. Kacira T, Kemerdere R, Atukeren P, Hanimoglu H, Zihni Sanus G, Kucur M, et al: Detection of capsace-3, neuron specific enolase, and high-sensitivity C-reactive protein levels in both cerebrospinal fluid and serum of patients after aneurysmal subarachnoid hemorrhage. Neurosurgery 60:674-680, 2007

29. Kassell NF, Sasaki T, Colohan ART, Nazar G: Cerebral vasospasm following aneurysmal subarachnoid hemorrhage. Stroke 16:562-572, 1985

30. Kasuya H, Shimizu T: Activated complement components $\mathrm{C} 3 \mathrm{a}$ and $\mathrm{C} 4 \mathrm{a}$ in cerebrospinal fluid and plasma following subarachnoid hemorrhage. J Neurosurg 71:741-746, 1989

31. Kasuya H, Weir BK, Shen Y, Hariton G, Vollrath B, Ghahary A: Procollagen type I and III and transforming growth factorbeta gene expression in the arterial wall after exposure to periarterial blood. Neurosurgery 33:716-722, 1993

32. Kasuya H, Weir BK, Nakane M, Pollock JS, Johns L, Marton LS, et al: Nitric oxide synthase and guanylate cyclase levels in canine basilar artery after subarachnoid hemorrhage. J Neurosurg 82:250-255, 1995

33. Kaynar MY, Tanriverdi T, Kafadar AM, Kacira T, Uzun H, Aydin S, et al: Detection of soluble intercellular adhesion molecule-1 and vascular cell adhesion molecule-1 in both cerebrospinal fluid and serum of patients after aneurysmal subarachnoid hemorrhage. J Neurosurg 101:1030-1036, 2004
34. Kubo Y, Ogasawara K, Kakino S, Kashimura H, Tomitsuka N, Sugawara A, et al: Serum inflammatory adhesion molecules and high-sensitivity C-reactive protein correlates with delayed ischemic neurologic deficits after subarachnoid hemorrhage. Surg Neurol 69:592-596, 2008

35. Kubota T, Handa Y, Tsuchida A, Kaneko M, Kobayashi H, Kubota T: The kinetics of lymphocyte subsets and macrophages in subarachnoid space after subarachnoid hemorrhage in rats. Stroke 24:1993-2001, 1993

36. Kuroki M, Kanamaru K, Suzuki H, Waga S, Semba R: Effect of vasospasm on heme oxygenases in a rat model of subarachnoid hemorrhage. Stroke 29:683-689, 1998

37. Lin CL, Jeng AY, Howng SL, Kwan AL: Endothelin and subarachnoid hemorrhage-induced cerebral vasospasm: pathogen- esis and treatment. Curr Med Chem 11:1779-1791, 2004

38. Macdonald RL, Weir B: Molecular biology and genetics, in Macdonald RL, Weir B (eds): Cerebral Vasospasm. San Diego: Academic Press 2001, pp 476-508

39. Matz PG, Massa SM, Weinstein PR, Turner C, Panter SS, Sharp FR: Focal hyperexpression of hemeoxygenase-1 protein and messenger RNA in rat brain caused by cellular stress following subarachnoid injections of lysed blood. J Neurosurg 85:892-900, 1996

40. Matz PG, Sundaresan S, Sharp FR, Weinstein PR: Induction of HSP70 in rat brain following subarachnoid hemorrhage produced by endovascular perforation. J Neurosurg 85:138145,1996

41. Matz P, Turner C, Weinstein PR, Massa SM, Panter SS, Sharp FR: Heme oxygenase-1 induction in glia throughout rat brain following experimental subarachnoid hemorrhage. Brain Res 713:211-222, 1996

42. Matz P, Weinstein P, States B, Honkaniemi J, Sharp FR: Subarachnoid injections of lysed blood induce hsp70 stress gene and produce DNA fragmentation in focal areas of the rat brain. Stroke 27:504-513, 1996

43. Mayberg MR, Batjer HH, Dacey RG Jr, Diringer M, Haley EC, Heros RC, et al: Guidelines for the management of aneurysmal subarachnoid hemorrhage: a statement for healthcare professionals from a special writing group of the Stroke Council, American Heart Association. Stroke 25:2315-2328, 1994

44. Mazlam MZ, Hodgson HJ: Interrelations between interleukin-6, interleukin-1 beta, plasma C-reactive protein values, and in vitro C-reactive protein generation in patients with inflammatory bowel disease. Gut 35:77-83, 1994

45. Mima T, Mostafa MG, Mori K: Therapeutic dose and timing of administration of RNA synthesis inhibitors for preventing cerebral vasospasm after subarachnoid hemorrhage. Acta Neurochir Suppl (Wien) 70:65-67, 1997

46. Onda H, Kasuya H, Takakura K, Hori T, Imaizumi T, Takeuchi $\mathrm{T}$, et al: Identification of genes differentially expressed in canine vasospastic cerebral arteries after subarachnoid hemorrhage. J Cereb Blood Flow Metab 19:1279-1288, 1999

47. Ono S, Zhang ZD, Marton LS, Yamini B, Windmeyer E, Johns L, et al: Heme oxygenase-1 and ferritin are increased in cerebral arteries after subarachnoid hemorrhage in monkeys. J Cereb Blood Flow Metab 20:1066-1076, 2000

48. Ostergaard JR, Kristensen BO, Svehag SE, Teisner B, Miletic $\mathrm{T}$ : Immune complexes and complement activation following rupture of intracranial saccular aneurysms. J Neurosurg 66:891-897, 1987

49. Osuka K, Suzuki Y, Watanabe Y, Takayasu M, Yoshida J: Inducible cyclo-oxygenase expression in canine basilar artery after experimental subarachnoid hemorrhage. Stroke 29:1219-1222, 1998

50. Pellettieri L, Carlson CA, Lindholm L: Is the vasospasm following subarachnoid hemorrhage an immunoreactive disease? Experientia 37:1170-1171, 1981 


\section{Levels of C-reactive protein and vasospasm in patients with aSAH}

51. Pellettieri L, Nilsson B, Carlsson CA, Nilsson U: Serum immunocomplexes in patients with subarachnoid hemorrhage. Neurosurgery 19:767-771, 1986

52. Peterson EW, Cardoso ER: The blood-brain barrier following experimental subarachnoid hemorrhage. Part I: Response to insult caused by arterial hypertension. J Neurosurg 58:338344, 1983

53. Pluta RM: Delayed cerebral vasospasm and nitric oxide: review, new hypothesis, and proposed treatment. Pharmacol Ther 105:23-56, 2005

54. Polin RS, Bavbek M, Shaffrey ME, Billups K, Bogaev CA, Kassell NF, et al: Detection of soluble E-selectin, ICAM-1, VCAM-1, and L-selectin in the cerebrospinal fluid of patients after subarachnoid hemorrhage. J Neurosurg 89:559-567, 1998

55. Provencio JJ, Vora N: Subarachnoid hemorrhage and inflammation; bench to bedside and back. Semin Neurol 25:435444,2005

56. Rothoerl RD, Axmann C, Pina AL, Woertgen C, Brawanski A: Possible role of C-reactive protein and white blood cell count in the pathogenesis of cerebral vasospasm following aneurysmal subarachnoid hemorrhage. J Neurosurg Anesthesiol 18:68-72, 2006

57. Rothoerl RD, Schebesch KM, Kubitza M, Woertgen C, Brawanski A, Pina AL: ICAM-1 and VCAM-1 expression following aneurysmal subarachnoid hemorrhage and their possible role in the pathophysiology of subsequent ischemic deficits. Cerebrovasc Dis 22:143-149, 2006

58. Schievink WI: Intracranial aneurysms. N Engl J Med 336:28-40, 1997

59. Shigeno T, Mima T, Yanagisawa M, Saito A, Goto K, Yamashita K, et al: Prevention of cerebral vasospasm by actinomycin D. J Neurosurg 74:940-943, 1991

60. Sills AK, Clatterbuck RE, Thompson RC, Cohen PL, Tamargo RJ: Endothelial expression of intercellular adhesion molecule-1 (ICAM-1) in experimental vasospasm. Neurosurgery 41:453-461, 1997
61. Soejima H, Miyamoto S, Kojima S, Hokamaki J, Tanaka T, Kawano H, et al: Coronary spastic angina in patients with connective tissue disease. Circ J 68:367-370, 2004

62. Suzuki H, Kanamaru K, Tsunoda H, Inada H, Kuroki M, Sun $\mathrm{H}$, et al: Heme oxygenase-1 gene induction as an intrinsic regulation against delayed cerebral vasospasm in rats. J Clin Invest 104:59-66, 1999

63. Takizawa T, Tada T, Kitazawa K, Tanaka Y, Hongo K, Kameko $\mathrm{M}$, et al: Inflammatory cytokine cascade released by leukocytes in cerebrospinal fluid after subarachnoid hemorrhage. Neurol Res 23:724-730, 2001

64. Tran Dinh YR, Jomaa A, Callebert J, Reynier-Rebuffel AM, Tedgui A, Savarit A, et al: Overexpression of cyclooxygenase-2 in rabbit basilar artery endothelial cells after subarachnoid hemorrhage. Neurosurgery 48:626-635, 2001

65. Umemoto S, Suzuki N, Fujii K, Fujii A, Fujii T, Iwami T, et al: Eosinophil counts and plasma fibrinogen in patients with vasospastic angina pectoris. Am J Cardiol 85:715-719, 2000

66. von Holst H, Ericson K, Edner G: Positron emission tomography with 68-Ga-EDTA and computed tomography in patients with subarachnoid hemorrhage. Acta Neurochir (Wien) 97:146-149, 1989

67. Wang X, Marton LS, Weir BK, Macdonald RL: Immediate early gene expression in vascular smooth muscle cells synergistically induced by hemosylate components. J Neurosurg 90:1083-1090, 1999

Manuscript submitted December 24, 2008.

Accepted January 23, 2009.

Address correspondence to: Kostas N. Fountas, M.D., Ph.D., Department of Neurosurgery, Building A, 3rd Floor, Suite \#56, University Hospital of Larisa Mezourlo, Larisa 41110, Greece. email: fountas@med.uth.gr. 